\title{
XLVI. Report of the Royal College of Physicians of London on vaccination. printed by order of the house of commons, dated 8th July 1807
}

\section{Lucas Pepys President}

To cite this article: Lucas Pepys President (1807) XLVI. Report of the Royal College of Physicians of London on vaccination. printed by order of the house of commons, dated 8th July 1807 , Philosophical Magazine Series 1, 28:112, 316-324, DOI: $10.1080 / 14786440708563526$

To link to this article: http://dx.doi.org/10.1080/14786440708563526

曲 Published online: 18 May 2009.

Submit your article to this journal $\pi$

Џll Article views: 1

Q View related articles $₫$ 
First Indication of the Mineralogical Inquiries necessary to. be made as to the Existence of Potash.

In an essay upon the art of making saltpetre, which I presented to the National Institute several years ago, I explained the origin of what is called natural soda, and I took that occasion to inquire what became of the potash confined in the lowels of the earth. About a year afterwards M. Klaproth discovered it in several volcanic productions; and his discovery was soon confirmed by M. Vauquelin. It is peculiarly gratifying to me to have suggested the idea of these useful researches.

\section{Proballe Origin of Natrum.}

I am strongly inclined to think that the natrum of the lakes in Egypt and other places owes its origin to the decomposition of the muriate of soda by potash, which is one of the products of the disorganization of vegetables; for the shores of the six lakes of Egypt, and the adjacent soils, are covered with jonquils and roses, which must annually furnish plenty of potash. It would be easy to verify this explanation by experiments, which promise more success than those which have been made with other views. To conclude: the explanation which I thus gave, previous to the late memorable travels of several of our learned men in Egypt, before it be confirmed, would require us to prove the coexistence of the muriate of potash along with the other salts, in the lakes of natrum and in the waters of the Nile.

XLVI. Report of the Royal College of Physicians of London on Vaccination. Printed by Order of the House of Commons, dated 8th July 1807 .

$T_{\text {he Royal College of Physicians of London, having re- }}$ ceived his majesty's commands, in compliance with an address from the house of commons " to inquire into the state of vaccine inoculation in the united kingdom, to report their 
opinion and observations upon that practice, upon the evidence which has been adduced in its support, and upon the causes which have hitherto retarded its general adoption," have applied themselves diligently to the business referred to them.

Deeply impressed with the importance of an inquiry which equally involves the lives of individuals and the public prosperity, they have made every exertion to investigate the subject fully and impartially. In aid of the knowledge and experience of the members of their own body, they have applied separately to each of the licentiates of the college; they have corresponded with the Colleges of Physicians of Dublin and Edinburgh ; with the Colleges of Surgeons of London, Edinburgh, and Dublin; they have called upon the societies established for vaccination, for an account of their practice, to what extent it has been carried on, and what has been the result of their experience; and they have, by public notice, invited individuals to contribute whatever information they had severally collected. They have in consequence been furnished with a mass of evidence, communicated with the greatest readiness and candour, which enables them to speak with confilence upon all the principal points referred to them.

I. During eight years, which have elapsed since Dr. Jenner made his discovery public, the progress of viccination has been rapid, not only in all parts of the united kingdom, but in every quarter of the civilized world. In the British islands some hundred thousands have been vaccinated; in our possessions in the East Indies upwards of 800,000 ; and among the nations of Europe the practice has become general. Professional men have submitted it to the fairest trials, and the public bave, for the most part, received it without prejudice. A few, indeed, have stood forth the adversaries of vaccination on the same grounds as their predecessors who opposed the inoculation for the small-pox, falsely led by hypothetical reasoning in the investigation of a subject which must be supported or rejected upon facts and observation only. With these few exceptions, the testimony in favour of vaccination has been most strong and satisfactory; and the 
practice of it, though it has received a check in some quarters, appears still to be upon the increase in most parts of the united kingdom.

II. The College of Physicians, in giving their observations and opinions on the practice of vaccination, think it right to premise, that they advance nothing but what is supported by the multiplied and unequivocal evidence which has been brought before them, and they have not considered any facts as proved but what have been stated from actual observation.

Vaccination appears to be in general perfectly safe ; the instances to the contrary being extremely rare. The disease excited by it is slight, and seldom prevents those under it from following their ordinary occupations. It has been communicated with safety to pregnant women, to children during dentition, and in their earliest infancy; in all which respects it possesses material advantages over inoculation for the small-pox; which, though productive of a disease generally mild, yet sometimes occasions alarming symptoms, and is in a few cases fatal.

The security derived from vaccination against the smallpox, if not absolutely perfect, is as nearly so as can perhaps be expected from any human discovery; for amongst several hundred thousand cases, with the results of which the college have been made acquainted, the number of alleged failures bas been surprisingly small, so much so, as to form certainly no reasonable objection to the general adoption of vaccination; for it appears that there are not nearly so many failures, in a given number of vaccinated persons, as there are deaths in an equal number of persons inoculated for the small-pox. Nothing can more clearly demonstrate the superiority of vaccination over the inoculation of the smallpox, than this consideration; and it is a most important fact, which has been confirmed in the course of this inquiry, that in almost every case where the small-pox has succeeded vaccination, whether by inoculation or by casual infection, the disease has varied much from its ordinary course; it has neither been the same in the violence nor in the duration or its symptoms, but has, with very few exceptions, been remarkably 
remarkably mild, as if the small-pox had been deprived, by the previous vaccine disease, of all its usual malignity.

The testimonies before the College of Pbysicians are very decicied in declaring, that vaccination does less mischief to the constitution, and less frequently gives rise to other diseases, than the small -pox, either natural or inoculated.

The college feel themselves called upon to state this strongly, because it has been objected to vaccination, that it produces new, unheard-of, and monstrous diseases. Of such assertions no proofs have been produced, and, after diligent inquiry, the college believe them to have been either the inventions of designing, or the mistakes of ignorant, men. 'In these respects then, in its mildness, its safety, and its consequences, the individual may look for the peculiar advantages of vaccination. The benefits which flow from it to society are infinitely more considerable; it spreads no infection, and can be communicated only by inoculation. It is from a consideration of the pernicious effects of the small-pox, that the real value of vaccination is to be estimated. The natural sinall-pox has been supposed to destroy a sixth part of all whom it attacks; and that even by inoculation, where that has been general in parishes and towns, about one in 300 has usually died. It is not sufficiently known, or not adverted to, that nearly one-tenth, some years more than one-tenth, of the whole mortality in London, is occasioned by the small-pox; and however beneficial the inoculation of the small-pox may have been to individuals, it appears to have kept up a constant source of contagion, which has been the means of increasing the number of deaths by what is called the natural disease. It cannot be doubted that this mischief has been extended by the inconsiderate manner in which great numbers of persons, even since the introduction of vaccination, are still every year inoculated with the small-pox, and afterwards required to attend two or three times a week at the places of moculation, through every stage of their illness.

From this, then, the public are to expect the great and uncontroverted superiority. of vaccination, that it commu- 
nicates no casual infection, and, while it is a protection to the individual, it is not prejudicial to the public.

III. The College of Physicians, in reporting their observations and opinıons on the evidence adduced in support of vaccination, feel themselves authorized to state, that a body of evidence so large, so temperate, and so consistent, was perhaps never before collected upon any medical question. A discovery so novel, and to which thene was nothing analogous known in nature, though resting on the experimental observations of the inventor, was at first received with diffidence: it was not, however, difficult for others to repeat his experiments, by which the truth of his observations was confirmed, and the doubts of the cautious were gradually dispelled by extensive experience. At the commencement of the practice, almost all that were vaccinated were afterwards submitted to the inoculation of the smallpox; many underwent this operation a second, and even a third time, and the uniform success of these trials quickly bred confidence in the new discovery But the evidence of the security derived from vaccination against the small-pox does not rest alone upon those who afterwards underwent variolous inoculation, although amounting to many thousands ; for it appears, from numerous observations communicated to the college, that those who have been vaccinated are equally secure against the contagion of epidemic smallpox. Towns indeed, and districts of the country, in which vaccination had been general, have afterwards had the smallpox prevalent on all sides of them without suffering from the contagion. There are also in the evidence a few examples of epidemic small-pox having been subdued by a general vaccination. It will not, therefore, appear extraordinary, that many who have communicated their observations should state, that though at first they thought unfavourably of the practice, experience had now removed all their doubts.

It has been already mentioned that the evidence is not universally favourable, although it is in truth nearly so; for there are a few who entertain sentiments differing widely from those of the great majority of their brethren. The college, 
college, therefore, deemed it their duty, in a particular manner, to inquire upon what grounds and evidence the opposers of vaccination rested their opinions. From personal examination, as well as from their writings, they endeavoured to learn the full extent and weight of their objections. They found them without experience in vaccination, supporting their opinions by hearsay information and hypothetical reasoning, and, upon investigating the facts which they advanced, they found them to be either misapprehended or misrepresented; or that they fell under the description of cases of imperfect small-pox, before noticed, and which the college have endeavoured fairly to appreciate.

The practice of vaccination is but of eight years standing, and its promoters, as well as opponents, must keep in mind, that a period so short is too limited to ascertain every point, or to bring the art to that perfection of which it may be capable. The truth of this will readily be admitted by those acquainted with the history of inoculation for the smallpox. Vaccination is now, however, well understood, and its character accurately described. Some deviations from the usual course have occasionally occurred, which the author of the practice has called spurious cow-pox, by which the public have been misled, as if there were a true and a false cow-pox; but it appears that nothing more was meant than to express irregularity or difference from that common form and progress of the vaccine pustule from which its efficacy is inferred. Those who perform vaccination ought therefore to be well instructed, and should have watched with the greatest care the regular progress of the pustule, and learnt the most proper time for taking the matter. There is little doubt that some of the failures are to be imputed to the inexperience of the early vaccinators, and it is not unreasonable to expect that further observations will yet suggest many improvements that will reduce the number of anomalous cases, and furnish the means of determining, with greater precision, when the vaccine disease has been effectually received.

Though the College of Physicians have confined themselves in estimating the evidence to such facts as have ocVol, 28. No, 112. Sept, 1807. X curred 
curred in their own country, because the accuracy of them could best be ascertained, they cannot be insensible to the confirmation these receive from the reports of the successful introduction of vaccination, not only into every part of Extrope, but throughout the vast continents of Asia and America.

IV. Several causes have had a partial operation in retarding the general adoption of vaccination; some writers have greatly undervalued the security it affords, while others have considered it to be of a temporary nature only; but if any reliance is to be placed on the statements which have been laid before the college, its power of protecting the human body from the small-pox, though not perfect indeed, is abundantly sufficient to recommend it to the prudent and dispassionate, especially as the small-pox, in the few instances where it has subsequently occurred, has been generally mild and transient. The opinion that vaccination affords but a temporary security, is supported by no analngy in nature, nor by the facts which have hitherto occurred. Although the experience of vaccine inoculation be only of a few years, yet the same disease, contracted by the milkers of cows, in some districts has been long enough known to ascertain that in them, at least, the unsusceptibility of the small-pox contagion does not wear out by time. Another cause is, the charge against vaccination of producing various new diseases of frightful and monstrous appearance.

Representations of some of these have been exhibited in prints in a way to alarm the feelings of parents, and to infuse dread and apprehension into the -minds of the uninformed. Publications with such representations have been widely circulated; and though they originate either in gross ignorance or wilful misrepresentation, yct have they Jessened the confidence of many, particularly of the lower classes, in vaccination: no permanent effects, however, in retarding the progress of vaccination need be apprehended from such causes, for, as soon as the public shall view them coolly and withont surprise, they will excite contempt and not fear.

Though the College of Physicians are of opinion that the progress of vaccination has been retarded in a few places by 
the above causes; yet they conceive that its general adoption has been prevented by causes far more powerful, and of a nature wholly different. The lower orders of society can hardly be induced to adopt precautions against evils which may be at a distance; nor can it be expected from them, if these precautions are attended with expense. Unless, therefore, from the immediate dread of epidemic smallpox, neither vaccination nor inoculation appear at any time to have been general, and when the cause of terror has passed by, the public have relapsed again into a state of indifference and apathy, and the salutary practice has come to a stand. It is not easy to suggest a remedy for an evil so deeply imprinted in human nature. To inform and instruct the public mind may do much, and it will probably be found that the progress of vaccination in different parts of the united kingdom will be in proportion to that instruction. Were encouragement given to vaccination, by offering it to the poorer classes without expense, there is little doubt but it would in time supersede the inoculation for the small-pox, and thereby various sources of variolous infection would be cut off; but till vaccination becomes general it will be impossible to prevent the constant recurrence of the natura! smallpox by means of those who are inoculated, except it should appear proper to the legislature to adopt, in its wisdom, some measure by which those who still, from terror or prejudice, prefer the small-pox to the vaccine disease, may, in thus consulting the gratification of their own feelings, be prevented from doing mischief to their neighbours.

From the whole of the above considerations the College of Physiciaus feel it their duty strongly to recommend the practice of vaccination. They have been led to this conclusion by no preconceived opinion, but by the most unbiassed judgment, formed from an irresistible weight of evidence which has been laid before them. For when the number, the respectability, the disinterestedness, and the extensive experience of its advocates, is compared with the feeble and imperfect testimonies of its few opposers; and when it is considered that many who were once adverse to raccination, have been convinced by further trials, and are 
now to be ranked among its warmest supporters, the truth seems to be estatlished as firmly as the nature of such a question admits; so that the College of Physicians conceive the public may reasonably look forward, with some degree of hope, to the time when all opposition shall cease, and the general concurrence of mankind shall at length be able to put an end to the ravages at least, if not to the existence, of the small-pox.

Royal College of Physicians,

Lucas Perys, President. 10th April 1807.

James Hervey, Register.

XLVII. Report of the King and Queen's College of Physicians in Ireland on Vaccination*.

$\mathrm{T}$

Dublin, Nov. 11, 1806. I HE practice of vaccination was introduced into this city about the beginning of the year 1801, and appears to have made inconsiderable progress at first. A variety of causes operated to retard its general adoption, amongst which the novelty of the practice, and the extraordinary effects attributed to vaccination, would naturally take the lead.

Variolous inoculation had been long, almost exclusively, in the hands of a particular branch of the profession, whose prejudices and interests were strongly opposed to the new practice; and by their being the usual medical attendants in families, and especially employed in the diseases of children, their opinions had greater effect upon the minds of parents. The small-pox is rendered a much less formidable disease in this country by the frequency of inoculation for it, than it is in other parts of his majesty's dominions, where prejudices against inoculation have prevailed; hence parents, not unnaturally, objected to the introduction of a new disease, rather than not recur to that, with the mildness and safety of which they were well acquainted.

* From Report on Vaccination, printed by order of the House of Commons, dated 8th July 1807 . 